Gut, 1988, 29, 149-152

\title{
Transpapillary iridium-192 wire in the treatment of malignant bile duct obstruction
}

\author{
M D LEVITT, B H LAURENCE, F CAMERON, AND P F B KLEMP \\ From the Departments of Gastroenterology and Radiotherapy, Sir Charles Gairdner Hospital, and the \\ Department of Medical Physics, Royal Perth Hospital, Perth, Western Australia
}

SUMmARY Twenty four patients with malignant bile duct obstruction were treated with intraluminal radiotherapy using iridium-192 wire inserted through an endoscopically placed nasobiliary catheter. Biliary drainage after treatment was maintained by an endoprosthesis. The median dose of intraluminal radiotherapy was $6000 \mathrm{cGy}$; two patients with cholangiocarcinoma were given a second course because of disease extension; four patients with pancreatic carcinoma received additional external irradiation $(3000 \mathrm{cGy})$. There was one early death from a cerebrovascular accident (30 day mortality, $4 \cdot 2 \%$ ). Cholangitis (30\%) was the major early complication and stent blockage $(40 \%)$ the major late complication; there were no complications directly attributable to radiotherapy. The median survival for patients with pancreatic carcinoma was 250 days and for cholangiocarcinoma, 300 days. This method is technically feasible and may prove safer than the transhepatic technique. The ability of intraluminal irradiation to improve palliation or lengthen survival in patients with malignant bile duct obstruction remains uncertain. Assessment by a prospective, controlled trial is essential.

Intracavitary irradiation is an accepted form of palliation in patients with oesophageal, gastric and rectal malignancy. ${ }^{12} \mathrm{~A}$ high dose of irradiation can be delivered to a limited volume of tissue over a short period - a significant advantage over conventional external radiotherapy. Intraluminal irradiation using iridium or radium placed transhepatically has been used to treat patients with malignant bile duct obstruction. ${ }^{3-8}$ It has been suggested that this form of treatment, together with catheter or endoprosthetic drainage for the relief of jaundice, may double the survival time in patients with hilar cholangiocarcinoma. ${ }^{9}$

Biliary decompression by the transhepatic route has a higher morbidity in malignant bile duct obstruction than the endoscopic transpapillary approach ${ }^{10}$; similar advantages might also be expected using this technique for placement of both the iridium-192 wire and the subsequent endoprosthesis. A method for the transpapillary administration of iridium-192 in patients with malignant bile duct obstruction has been evaluated.

Address for correspondence: Dr B H Laurence, GE Unit, Sir Charles Gairdner Hospital, Nedlands, Western Australia, 6009.

Received for publication 31 July 1987.

\section{Methods}

PATIENTS

Between June 1983 and September 1986, 24 patients were given intraluminal iridium-192 wire irradiation for malignant bile duct obstruction. There were 13 men and 11 women, median age, 69 years (57-87). Obstructive jaundice was the result of carcinoma of the head of pancreas in 11 patients, cholangiocarcinoma in seven (all below the bifurcation), hilar lymph node metastases in three, carcinoma of the gall bladder in two and ampullary carcinoma in one. Histologic confirmation of the diagnosis was obtained in 19 patients $(79 \%)$. The subsequent clinical course in the remaining five patients was consistent with the radiologic diagnosis of a malignant stricture.

\section{DRAINAGE TECHNIQUE}

At the initial ERCP a 6 or 7 Fr catheter was passed through the biliary obstruction, rerouted through the nose and drained externally ${ }^{11} ;$ a barb on the catheter above the stricture prevented downward displacement. After completion of intraluminal irradiation the nasobiliary tube was removed and, at a second ERCP, an endoprosthesis was inserted using a stan- 


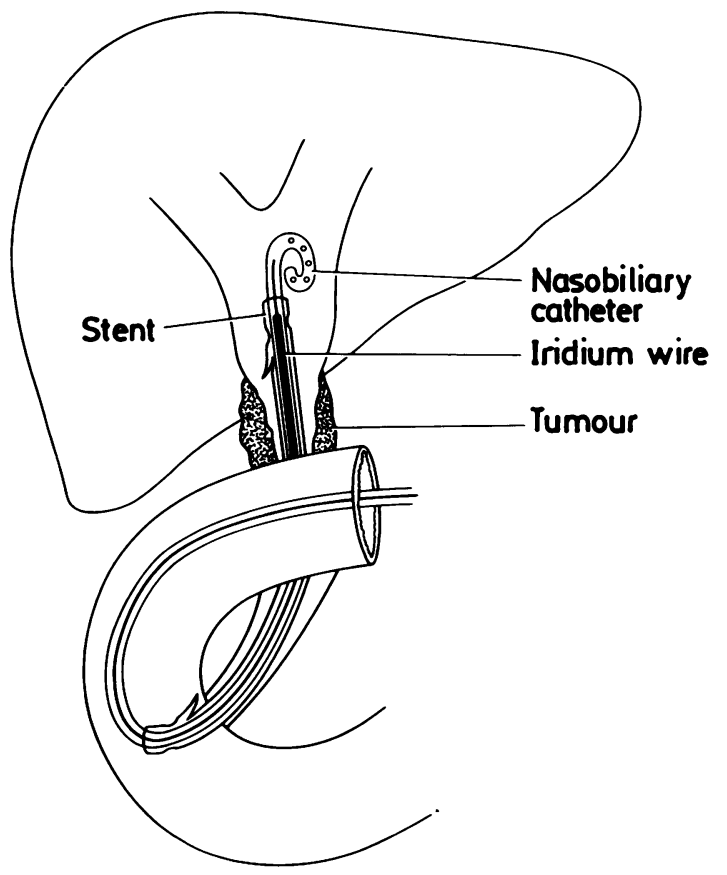

Fig. 1 Combined insertion of stent and nasobiliary catheter.

dard technique ${ }^{12}$; since the availability of widechannel duodenoscopes the stent and nasobiliary catheter have been inserted at the initial procedure (Fig. 1). In one patient the catheter could not be negotiated through the obstruction and was inserted percutaneously; subsequent iridium-192 therapy and endoprosthesis insertion were carried out by this route.

Iridium-192 therapy was administered through the nasobiliary catheter in 23 patients and stents (8-10 Fr) were successfully placed in 20 . Surgical bypass (two patients) and percutaneous stent insertion (one patient) were necessary for relief of jaundice in the other three.

IRIDIUM-192 WIRE LOADING

The length of iridium-192 wire used was equivalent to

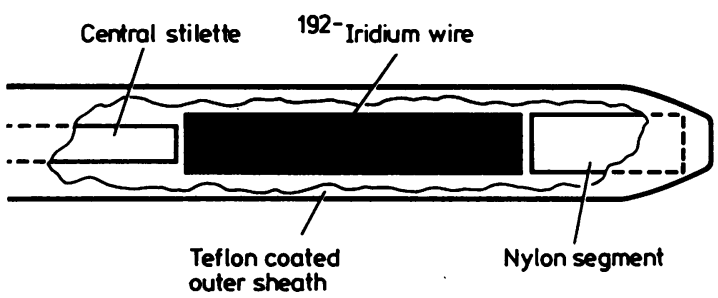

Fig. 2 Iridium-192 wire within distal end of nasobiliary catheter.
1.5 times the length of the malignant stricture, allowing for $25 \%$ overlap of the stricture at either end. Trimming of the duodenal end of the wire was required for distal strictures to prevent irradiation of the duodenal mucosa.

A movable core, Teflon coated guidewire $(0.088$ mm diameter, $145 \mathrm{~cm}$ long, Medrad TM351451) was used. The stilette was removed and a $1-2 \mathrm{~cm}$ nylon thread inserted followed by the length of iridium-192 wire. The stilette was replaced and the iridium-192 wire with the nylon thread were pushed to the sealed distal end of the Teflon sheath (Fig. 2). The loaded guidewire was heat sterilised in an autoclavable transport container. ${ }^{13}$

The upper limit of the malignant stricture was delineated by a nasobiliary cholangiogram and the loaded guidewire was then passed down one limb of a Y-connector (Cook PSFLL-PCF-MLL-30) attached to the proximal end of the nasobiliary catheter. Positioning of the iridium-192 segment across the stricture was facilitated by the greater radiodensity of the iridium-192 wire compared with the outer sheath of the guidewire. The guidewire was fixed proximally within its limb of the Y-connector to prevent dislodgement; external bile drainage was established through the other limb. Prophylactic antibiotics were given routinely.

Therapy was designed to administer $6000 \mathrm{cGy}$ with $100 \%$ of the dose delivered at a distance of $0.5 \mathrm{~cm}$ from the iridium-192 wire. Dislodgement of the nasobiliary catheter occurred in three patients. In one of these, the catheter was repositioned and the course of intraluminal irradiation completed; in the other two no further intraluminal irradiation was attempted (4100 and 4500 cGy delivered). The duration of therapy was determined by the length and radioactivity of the Iridium-192 wire, and the dose rate (estimated from a locally calculated 'escargot' similar to the Paris system $\left.{ }^{14}\right)$. The median duration of intraluminal therapy was 90 hours $(70-109)$.

Four patients, each with carcinoma of the head of pancreas, received a course of external radiotherapy shortly after completion of intraluminal irradiation. Two patients, both with cholangiocarcinoma, underwent a second course of intraluminal irradiation for extension of their disease at 439 and 1065 days.

The field of external radiotherapy was planned while the nasobiliary tube was in situ and was administered one to four weeks after completion of the intraluminal irradiation. A total of $3000 \mathrm{cGy}$ was delivered by a $4 \mathrm{MEV}$ linear accelerator in 10 fractions over two weeks using AP/PA fields to a volume not exceeding $10 \times 10 \mathrm{~cm}$ even if the tumour exceeded this. The field was planned to ensure that not more than $50 \%$ of the right kidney was included in the treatment volume. 


\section{HANDLER SAFETY}

The maximum dose to the hands of the operator has been of the order of 200 microSV per loading; with the use of shielding and long forceps for manipulation of the wire the exposure to the remainder of the body is less than 100 microSV per loading. This is well within accepted radiation safety limits. The nursing attendants may safely spend up to one hour per week at $50 \mathrm{~cm}$ from a patient undergoing treatment.

\section{Results}

There was one death caused by a cerebrovascular accident, 10 days after treatment giving a 30 day mortality of $4 \cdot 2 \%$. A further 20 patients have since died of their malignancy from 60-532 days after completion of intraluminal irradiation. Three patients are alive at 44,77 , and 1100 days. The overall median survival from the completion of therapy for patients with carcinoma of the head of pancreas was 250 days (approximately 8.3 months) and for cholangiocarcinoma 300 days (10 months).

Successful biliary decompression - the reduction of serum bilirubin concentrations to less than three times the normal range by the time of discharge - was achieved in 13 patients $(65 \%)$. Bilirubin continued to fall after discharge in most of the remaining patients.

Early complications occurred in 11 patients $(48 \%)$. Cholangitis was the most frequent and serious of these (seven patients, $30 \%$ ) but all responded to antibiotic therapy. Pancreatitis, sepsis after a fine needle aspiration biopsy, a selflimiting bile leak and bleeding from a duodenal ulcer were seen in one patient each.

Blockage of the endoprosthesis was the major late complication; in 12 patients $(60 \%)$, however, the first stent was still functioning at the time of death. Of the remaining eight patients, stent removal and replacement was required because of obstruction complicated by cholangitis in seven; four patients underwent two to five stent changes in all. The remaining patient, with pancreatic carcinoma complicated by recurrent jaundice and duodenal obstruction, was submitted to surgical bypass. The overall median survival of the initial endoprosthesis was 131 days (4.4 months), and for all endoscopically-placed stents was 93 days ( $3 \cdot 1$ months).

Two patients with carcinoma of the head of pancreas developed malignant duodenal obstruction necessitating surgical bypass at 109 and 245 days. There was no immediate (nausea, leucopenia), or longterm (fistula formation) morbidity attributable to intraluminal irradiation alone.

The median time spent in hospital after iridium192 therapy (23 patients) was 11 days (1-60); this varied with the presence or absence of early compli- cations. In the 11 patients without early complications the median duration of post-treatment hospitalisation was nine days (1-26); in the presence of early complications (12 patients) this duration was increased to $23 \cdot 5$ days $(5-60)$.

\section{Discussion}

The 30-day mortality of $4 \cdot 2 \%$ for intraluminal irradiation and endoscopic stent drainage compares favourably with that for endoscopic biliary drainage alone $\left(8-19 \%^{15-17}\right)$ or palliative surgical bypass (6$19 \%$ for pancreatic carcinoma ${ }^{18-20} 11-35 \%$ for cholangiocarcinoma $\left.{ }^{21-23}\right)$. In the only comparable study of iridium-192 therapy, ${ }^{9}$ the hospital mortality using the transhepatic approach was $3 \cdot 3 \%$. The mortality associated with iridium-192 therapy is clearly low and certainly no worse than that for palliative stenting alone.

The incidence of cholangitis $(30 \%)$ is considerably higher than that after endoscopic stent insertion without intraluminal irradiation $\left(19 \%{ }^{10}\right)$. Karani et $a l^{4}$ reported cholangitis in 12 of 30 patients $(40 \%)$, it being a contributory factor to death in two cases. Although Molt $e t$ a $l^{24}$ did not encounter a single case of cholangitis attributable to transhepatic intraluminal irradiation in 15 patients, cholangitis must still be regarded as a major hazard of iridium-192 therapy by either the transhepatic or transpapillary route.

The increased risk of cholangitis may be because of impaired bile drainage through the nasobiliary tube with the contained guidewire. The simultaneous insertion of stent and nasobiliary tube at the initial ERCP (Fig. 1) might be expected to improve drainage during the period of intraluminal irradiation and reduce the risk of cholangitis; it also eliminates the need for a second ERCP for final stent insertion. At the initial procedure the stent $(10-11.5 \mathrm{Fr})$ is passed over the biliary catheter and positioned across the obstruction; on completion of intraluminal irradiation the pigtail catheter is straightened with a guidewire and withdrawn under fluorescopic control leaving the stent in situ. This technique has been done successfully in three patients, an insufficient number to determine if the incidence of cholangitis is lowered.

In the absence of a control group treated by biliary stent alone, survival figures after iridium-192 therapy are difficult to interpret. In this and other ${ }^{24}$ series, however, survival was not significantly greater than after palliative drainage or bypass alone (pancreatic carcinoma, six to seven months ${ }^{182025}$; cholangiocarcinoma, 8-19 months ${ }^{926}$ ).

The transpapillary technique of intraluminal irradiation is technically feasible and may prove safer 
than the transhepatic approach. Iridium-192 therapy by either route, however, is associated with a higher incidence of cholangitis than with an endoprosthesis alone. To justify this added risk some benefit in terms of increased longevity or improved quality of life must be shown. A controlled trial of intraluminal irradiation against endoprosthesis alone in patients with malignant bile duct obstruction is required.

MDL was the 1986 Daisy Hill Fellow in Gastroenterology. We acknowledge the support of the Daisy Hill Trust for providing this sponsorship.

\section{References}

1 Rowland CG, Pagliero KM. Intracavitary irradiation in palliation of carcinoma of oesophagus and cardia. Lancet 1985; ii: 981-2.

2 Basrur VR, Knight KR. Intracavitary radiation for rectal carcinoma. J Can Assoc Radiol 1983; 34: 42-46.

3 Ikeda H. Intraluminal irradiation with iridium-191 wires for extrahepatic bile duct carcinoma. Nippon Igaku Hoshasen Gakkai Zasshi 1979; 39: 1356-1538.

4 Conroy RM, Shahbazian AA, Edwards KC, et al. A new method for treating carcinomatous biliary obstruction with intracatheter radium. Cancer 1982; 49: 1321-7.

5 Fletcher MS, Dawson JL, Wheeler PG, Brinkley D, Nunnerly $H$, Williams R. Treatment of high bile duct carcinoma by internal radiotherapy with Iridium-192 wire. Lancet 1981 ; ii: 172-4.

6 Herskovic A, Heaston D, Engler MJ, Fishburn RI, Jones RS, Noell KT. Irradiation of biliary carcinoma. Radiology 1981; 139: 219-22.

7 Mornex F, Gerard J-P, Bret P, Partensky C. Iridium wire radiotherapy for high bile duct carcinoma. Lancet 1981 ; ii: 479.

8 Phillip J, Hagenmuller F, Manegold J, Szepesi S, Classen M. Endoscopic intraductal radiotherapy of high bile duct carcinoma. Dtsch Med Wochenschr 1984; 109: 422-6.

9 Karani J, Fletcher M, Brinkley D, Dawson JL, Williams $R$, Nunnerly $H$. Internal biliary drainage and local radiotherapy with iridium-192 wire in treatment of hilar cholangiocarcinoma. Clin Radiol 1985; 36: 603-6.

10 Speer AG, Cotton PB, Hatfield A, et al. Randomized trial comparing endoscopic and percutaneous prostheses in poor risk patients with malignant obstructive jaundice [Abstract]. Gut 1985; 26:A1135.

11 Cotton PB, Burney PGJ, Mason RR. Trans-nasal bile duct catheterisation after endoscopic sphincterotomy. Gut 1979; 20: 285.
12 Laurence BH, Cotton PB. Decompression of malignant biliary obstruction by duodenoscopic intubation of the bile duct. $\mathrm{Br}$ Med J 1980; i: 522-3.

13 Deans T, Rafferty. An autoclavable transport container for guide-wires containing iridium 192. Br J Radiol 1986; 59: $1223-4$.

14 Pierquin B, Dutreix A, Paine $\mathrm{CH}$, Chassagne D, Marinello G, Ash D. The Paris system in interstitial radiotherapy. Acta Radiol Oncol 1978; 17: 33-48.

15 Huibregtse K, Tytgat GN. Endoscopic placement of biliary prostheses. In: Salmon PR, ed. Gastrointestinal endoscopy: advances in diagnosis and therapy. Vol I. London: Chapman \& Hall, 1983: 219-31.

16 Hagenmuller F. Results of endoscopic bilioduodenal drainage in malignant bile duct stenoses. In: Classen $\mathbf{M}$, Geenen J, Kawai K, eds. Non-surgical biliary drainage. Berlin: Springer-Verlag, 1984: 93-104.

17 Leung JWC, Yin TP, Speer AG, Cotton PB. Endoscopic palliation of malignant obstructive jaundice with a new 10 French gauge biliary stent [Abstract]. Gastrointest Endosc 1985; 31: 140 A63.

18 Vanheerden J, Heath P, Alden C. Biliary bypass for ductal adenocarcinoma of the pancreas. Mayo Clinic Experience, 1970-1975. Mayo Clinic Proc 1980; 55: 537-40.

19 Morrow M, Hilaris, B, Brennan MF. Comparison of conventional surgical resection, radioactive implantation, and bypass procedures for exocrine carcinoma of the pancreas 1975-1980. Ann Surg 1984; 199: 1-5.

20 Brooks DC, Osteen RT, Gray EB, et al. Evaluation of palliative procedures of pancreatic cancer. Am J Surg 1981; 141: 430-3.

21 Tompkins RK, Thomas D, Wile A, Longmire WP. Prognostic factors in bile duct carcinoma. Ann Surg 1981; 194: 447-57.

22 Evander A, Fredlund P, Hoevels J, Ihse I, Bengmark S. Evaluation of aggressive surgery for carcinoma of the extrahepatic bile ducts. Ann Surg 1980; 191: 23-9.

23 Blumgart LH, Benjamin IS, Hadjis NS, Beazley R. Surgical approaches to cholangiocarcinoma at confluence of hepatic ducts. Lancet 1984; i: 66-70.

24 Molt P, Hopfan S, Watson RC, Botet JF, Brennan MF. Intraluminal radiation therapy in the management of malignant biliary obstruction. Cancer. 1986; 57: 536-44.

25 Huibregtse $\mathrm{K}$, Katon RN, Coene PP, Tytgat GN. Endoscopic palliative treatment in pancreatic cancer. Gastrointest Endosc 1986; 32: 334-8.

26 Broe PJ, Cameron JL. The management of proximal biliary tract tumours. In: Mclean LD, ed. Advances in surgery Vol 15. Chicago: Chicago Yearbook Medical Publishers, 1984: 172-4. 